Aim of the study: Chemotherapeutic treatment in children and adolescents carries a risk of congenital tooth disorders and dentinoma. Study objective is to assess the correlation between tooth abnormalities, early complications of multidrug chemotherapy, and chemotherapeutics used in different antineoplastic therapies in children and adolescents.

Material and methods: Enamel defects (developmental defects of enamel index - DDE index) and defects in tooth number, size, and structure were assessed clinically and radiologically in 60 patients who underwent chemotherapy on average $4.9 \pm 3.4$ years earlier (PCH), and 60 generally healthy subjects (control group - CG), aged 6-18 years. Höltta's defect index (Del) was calculated. Medical files provided information on neoplasm type, age at treatment start and chemotherapy duration, chemotherapeutic type and dose, vomiting, and mucositis (CTCAE v4.0). Statistical significance of differences between groups was assessed with the Mann-Whitney $U$ test and the correlation between dental defects and chemotherapy with Spearman's rank correlation coefficient (significance $p \leq 0.05$ ).

Results: Enamel defects, tooth agenesis, microdontia, root resorption, taurodontism, and dentinoma occurred statistically significantly more often in the $\mathrm{PCH}$ group. A correlation was es tablished between vincristine use and dose and all types of dental defects; cyclophosphamide, doxorubicin, and isophosphamide and hypodontia; microdontia, root resorption, and enamel defects; etoposide and cisplatin and microdontia, root resorption, and enamel defects; methotrexate root resorption and enamel defects; carboplatin and dentinoma and enamel defects. Mucositis and vomiting promoted root resorption, microdontia, and enamel defects.

Conclusions: Dental defects are related to both the use of respective chemotherapeutics, especially vincristine, cyclophosphamide, doxorubicin, and isophosphamide, and to early complications in multidrug chemotherapy - mucositis and vomiting. Vincristine and carboplatin use may promote dentinoma.

Key words: neoplasm, chemotherapy, children, enamel defects, agenesis, microdontia, congenital root abnormalities.

Contemp Oncol (Pozn) 2016; 20 (5): 394-401 DOI: $10.5114 /$ wo. 2016.64602

\section{Antineoplastic chemotherapy and congenital tooth abnormalities in children and adolescents}

\author{
Ewa Krasuska-Sławińska', Agnieszka Brożyna², \\ Bożenna Dembowska-Bagińska², Dorota Olczak-Kowalczyk ${ }^{3}$
}

${ }^{1}$ Department of Paediatric Dental Surgery, Children's Memorial Hospital, Warsaw, Poland ${ }^{2}$ Department of Paediatric Oncology, Children Memorial Hospital, Warsaw, Poland ${ }^{3}$ Department of Paediatric Dentistry, Warsaw Medical University, Poland

\section{Introduction}

Multidrug chemotherapy allows effective treatment of more than $70 \%$ of children with neoplasms, independently of the disease type or stage [1-9]. Unfortunately, chemotherapeutics are not selective and have a low therapeutic index, which results in damaging also healthy cells. To increase therapy effectiveness and, at the same time, minimise its side effects, several chemotherapeutic agents, with different mechanisms of action, at minimal therapeutic doses tolerated by the host, are used in multidrug chemotherapy. Unfortunately, even despite that, chemotherapy presents risks of side effects, i.e. early and late complications.

Children under antineoplastic treatment in early childhood present more often tooth aplasia, microdontia, root resorption, and congenital enamel defects than generally healthy children. Taurodontism, enlarged pulp chamber, and supernumerary teeth also occurred more often [10-43].

Congenital defects, which often occur in neoplasms or are early chemotherapy complications, may result from fever, metabolic disorders and hormonal imbalance, and malnutrition. Chemotherapeutics may also have a direct impact on dental tissues; e.g. vincristine, colchicine, and vinblastine temporarily impair odontoblast activity [7, 43-45]. Chemotherapy probably also delays the development of the Hertwig sheath [23].

Multidrug chemotherapy makes it more difficult to assess the impact of respective drugs on odontogenesis and tooth pulp. Up to now, most researchers have assessed the impact of chemotherapy on teeth in children with leukaemia. There is little information on the effects of chemotherapeutics in other neoplasm therapies, although brain and germ cell tumours are common under the age of five years.

The present study aims to assess the correlation between the prevalence of congenital defects in permanent teeth and early complications of multidrug chemotherapy and chemotherapeutics used in various neoplasms in children.

\section{Material and methods}

Patients

The study was approved by the Children's Memorial Hospital Commission for bioethics on May 12, 2010 (permit 95/KBE/2010), and patients/their legal guardians consented to participate in the research study.

One hundred and twenty patients under the age of 18 years, including 60 who completed chemotherapeutic treatment for neoplasms at least one year earlier (PCH group; mean age $11.81 \pm 3.87$ years) at the Oncology Clinic of the Children's Memorial Hospital, and 60 generally healthy patients (CG control group; mean age $12.22 \pm 3.63$ years), treated at the Paediatric Dental 
Clinic of the Children's Memorial Hospital, were examined. Children with chronic diseases other than neoplasms, or undergoing or having undergone chronic treatments, or after radiation therapy in the head and neck region, were excluded from the research study. Patients from both groups were of similar socioeconomic status.

\section{Methods}

\section{Retrospective analysis of medical files}

Patient medical files were analysed for information on neoplasm type, age at treatment start, antineoplastic treatment duration, chemotherapeutic type and dose, and early chemotherapy complication prevalence and severity, i.e. vomiting and mucositis according to CTCAE v4.0 [46]. Accumulated doses that every patient received under treatment were calculated. All doses were then converted into $\mathrm{mg} / \mathrm{m}^{2}$.

\section{Dentition}

All tooth surfaces were clinically assessed in successive quadrants. Tooth number, congenital disorders, including anatomic crown size and shape, and enamel defects were assessed with the modified DDE index (opacities, hypoplasia, and combination of both) [47].

Pantomographs served to assess congenital disorder prevalence: no tooth buds (agenesis was diagnosed when there was no tooth/tooth bud after extraction was ruled out), hypodontia, microdontia (when tooth width was smaller or equal to half of the normal size), anatomic crown disorders, i.e. resorption, V-shape, U-shape, taurodontism (in the case of excessive vertical elongation of the tooth chamber with no tooth neck, and a lowered root bifurcation in multiradicular teeth) [23, 47-49]. Höltta's defect index (Del) was used [23].

No bud of the first premolar in children aged less than five years or of the second premolar and second molar in children under six years old, as well as poor visibility of teeth on the pantomograph, led to exclusion from the assessment. Furthermore, teeth with unfinished root development or with important root curves, teeth with attrition, abrasion or anatomic crown fracture, and third molars were also excluded from root assessment.

The assessed teeth were attributed the following codes: - D0 - no congenital disorders; ratio R/C > 1.6,

- D1 - ratio R/C from 1.6 to 1.2 - mild root resorption,

- D2 - ratio R/C from 1.1 to 0.9 - severe root resorption,

- D3 - ratio $\mathrm{R} / \mathrm{C}<0.9$ - severe root resorption,

- D4-microdontia,

- D5 - no tooth (aplasia).

Root length assessment included the longest root in multiradicular teeth, and the longest buccal root in mandibular molars and premolars. Crown height was calculated with measurement points at the line crossing through the incisive side of front teeth and buccal cusps of premolars and molars. R/C, i.e. the ratio of root length (R) to crown length (C), was calculated.

The prevalence of congenital disorders in respective teeth was assessed, and Del was calculated with the formula $(\mathrm{nD} 1 \times 1)+(\mathrm{nD} 2 \times 2)+(\mathrm{nD} 3 \times 3)+(\mathrm{nD} 4 \times 4)+(\mathrm{nD} 5$ $\times 5)$, where $n$ was the number of teeth with respective D1, D2, D3, D4, and D5 codes.

\section{Statistical analysis}

Results were statistically analysed with the nonparametric Mann-Whitney $U$ test (after a preliminary analysis of the compatibility of numeric values distribution with real distribution with the Shapiro-Wilk test). The impact of chemotherapy-related factors on dentition was assessed with Spearman's rho. Statistical significance was set at $p \leq 0.05$.

\section{Results}

The mean age at chemotherapy start was $5.9 \pm 4.0$ years, and treatment duration was $1.3 \pm 0.5$ years. On average, $4.9 \pm 3.4$ years elapsed since chemotherapy completion. Chemotherapy was used to treat: Burkitt's lymphoma (15.0\%), nephroblastoma (13.0\%), neuroblastoma (10.0\%), histiocytosis (8.3\%), rhabdomyosarcoma (6.7\%), Ewing's sarcoma (6.7\%), medulloblastoma (5.0\%), neurofibromatosis type I (5.0\%), and others (19.7\%). The treatment protocols were appropriate for the respective diagnosis. The drugs most often used in combination therapy included: vincristine (VCR), cyclophosphamide (CTX), doxorubicin (ADM), etoposide (VP-16), cisplatin (CDDP), ifosfamide (IF), and actinomycin (ACTD). Other drugs were used in $<15 \%$ of patients. Table 1 presents the antineoplastic treatments.

\section{Dentition}

Enamel defects were observed statistically significantly more often in PCH than in controls (Table 2). PCH also presented higher mean numbers of teeth with opacities (6.316 \pm 6.10 vs. $1.866 \pm 2.64 ; p=0.000)$ and hypoplasia $(1.516 \pm 3.61$ vs. $0.15 \pm 0.55 ; p=0.003)$. There was no significant difference $(0.533 \pm 1.83$ vs. $0.083 \pm 0.38$ respectively; $p=0.06)$ between mean numbers of teeth with a combination of enamel defects. Spearman's rho analysis revealed a positive correlation between enamel defect prevalence and age at chemotherapy start and its duration. Vomiting and the use and doses of vincristine, carboplatin, cyclophosphamide, doxorubicin, ifosfamide etoposide, and cisplatin were linked to the prevalence of opacities. Vincristine, methotrexate and mucositis showed a positive correlation with hypoplasia (Table 3).

Dental defects visible on pantomographs occurred statistically significantly more often in $\mathrm{PCH}$ than in controls (53.3\% vs. $76.7 \% ; p=0.0077$ ). More than one congenital defect $(p=0.0000)$ occurred in $46.7 \%$ of patients after chemotherapy, and only in $10 \%$ of controls ( $p=0.0000)$. Root resorption was the most common defect (Table 2). The prevalence of short roots and the mean Del component related to this defect (D1 + D2 + D3) were statistically significantly higher in $\mathrm{PCH}$ than in CG. Severe and very severe root absorption (38.33\% vs. 6.66\%; $p=0.0000$ ) occurred significantly more often in this group. In PCH the resorption occurred more often in first molar roots (in $21.6 \%$ of patients), and less often in incisors (15\%), premolars (15\%), and second molars (10\%). In controls it most often (5.0\% of subjects) occurred in first molars. Gener- 
Table 1. PCH patient characteristics

\begin{tabular}{lcc} 
Chemotherapeutic agent & $n$ & $\begin{array}{c}\text { Mean dose } \pm \text { SD } \\
\left(\mathrm{mg} / \mathrm{m}^{2}\right)\end{array}$ \\
Vincristine (VCR) & $53 / 88.0$ & $10.46 \pm 8.0$ \\
Cyclophosphamide (CTX) & $41 / 68.3$ & $5287.18 \pm 12233.51$ \\
\hline Doxurubicin (ADM) & $40 / 66.5$ & $167.41 \pm 152.43$ \\
\hline Etoposide (VP-16) & $39 / 65.0$ & $1434.58 \pm 1712.87$ \\
\hline Cisplatin (CDDP) & $26 / 43.03$ & $255.92 \pm 402.08$ \\
\hline Ifosfamide (IF) & $25 / 41.6$ & $12511.67 \pm 21032.63$ \\
\hline Actinomycin (ACTD) & $18 / 30.0$ & $3.06 \pm 8.54$ \\
\hline Dacarbazine (DTIC) & $17 / 28.3$ & $1649.14 \pm 2757.64$ \\
\hline Methotrexate (MTX) & $13 / 21.6$ & $3795.90 \pm 8195.43$ \\
\hline Carboplatin (CBDCA) & $11 / 18.3$ & $1478.70 \pm 7148.41$ \\
\hline Vinblastine (VBL) & $8 / 13.3$ & $15.33 \pm 56.24$ \\
\hline Cytarabine (Ara-C) & $8 / 13.3$ & $1592.86 \pm 5498.39$ \\
\hline Teniposide (VM-26) & $7 / 11.6$ & $155.67 \pm 446.76$ \\
\hline 5-Fluorouracil (5-FU) & $3 / 5.0$ & $83.33 \pm 457.95$ \\
\hline Bleomycin (BLM) & $2 / 3.3$ & $3.00 \pm 17.06$ \\
\hline Irinotecan (IRI) & $2 / 3.3$ & $38.33 \pm 247.72$ \\
\hline
\end{tabular}

Table 3. Statistically significant Spearmen's rho for enamel defects and factors related to used anti-neoplastic treatment

\begin{tabular}{|c|c|c|c|}
\hline & Opacities & Hypoplasia & $\begin{array}{l}\text { Combination } \\
\text { of defects }\end{array}$ \\
\hline $\begin{array}{l}\text { Age at chemotherapy } \\
\text { start }\end{array}$ & $0.2955^{\star}$ & $0.1845^{\star}$ & $0.1568^{*}$ \\
\hline Treatment duration & $0.1943^{\star}$ & $0.1980^{*}$ & 0.1459 \\
\hline VCR & $0.2536^{\star}$ & $0.1513^{*}$ & 0.0689 \\
\hline Dose & $0.2401^{*}$ & 0.1186 & 0.0837 \\
\hline CBDCA & $0.1504^{\star}$ & 0.0164 & 0.0148 \\
\hline Dose & $0.1493^{\star}$ & -0.0089 & -0.0057 \\
\hline CTX & $0.1834^{\star}$ & 0.1136 & 0.0459 \\
\hline Dose & $0.2034^{\star}$ & 0.1198 & 0.0761 \\
\hline ADM & $0.1937^{\star}$ & 0.1219 & 0.0287 \\
\hline Dose & $0.2042^{*}$ & 0.0834 & 0.0239 \\
\hline IF & $0.1874^{\star}$ & 0.0355 & -0.0249 \\
\hline Dose & $0.1720^{*}$ & 0.0339 & -0.0201 \\
\hline MTX & 0.0557 & $0.1546^{*}$ & 0.0535 \\
\hline Dose & 0.0543 & $0.1568^{*}$ & 0.0524 \\
\hline VP-16 & $0.3239^{*}$ & 0.0696 & 0.0208 \\
\hline Dose & $0.2907^{\star}$ & 0.0724 & 0.0058 \\
\hline CDDP & $0.2436^{\star}$ & 0.0915 & 0.0772 \\
\hline Dose & $0.2536^{*}$ & 0.0612 & 0.0517 \\
\hline Mucositis & $0.1785^{\star}$ & 0.1246 & 0.1395 \\
\hline Grade 2 & 0.1391 & $0.2099^{*}$ & $0.2023^{*}$ \\
\hline Vomiting & $0.2550^{*}$ & 0.0246 & 0.0271 \\
\hline
\end{tabular}

Table 2. Congenital disorders and Del in patients after anti-neoplastic treatment and in the control group

\begin{tabular}{|c|c|c|c|}
\hline \multirow[t]{2}{*}{ Congenital disorders } & $\mathrm{PCH}$ & CG & \multirow[t]{2}{*}{$p$} \\
\hline & \multicolumn{2}{|c|}{$n / \%$} & \\
\hline Enamel defects & $53 / 88.3$ & $24 / 40.0$ & $0.000^{*}$ \\
\hline opacities (DDE index: 1, 2, 5) & $34 / 56.6$ & $19 / 32.3$ & $0.006^{*}$ \\
\hline hypoplasia (DDE index: 3) & $7 / 11.6$ & $1 / 1.6$ & $0.001^{*}$ \\
\hline $\begin{array}{l}\text { combination of lesions (DDE } \\
\text { index: } 6,7 \text { ) }\end{array}$ & $12 / 20$ & $4 / 6.6$ & 0.068 \\
\hline Root resorption (D1 + D2 + D3) & $36 / 60.0$ & $25 / 41.6$ & $0.0450^{*}$ \\
\hline V-shaped & $18 / 30.00$ & $0 / 0.0$ & $0.0000^{*}$ \\
\hline Microdontia (D4) & $12 / 21.67$ & $0 / 0.0$ & $0.0003^{*}$ \\
\hline no tooth bud (D5) & $16 / 26.67$ & $4 / 6.66$ & $0.0035^{*}$ \\
\hline Del $>0$ & $45 / 75.00$ & $2643.33 /$ & $0.0004^{*}$ \\
\hline \multirow[t]{2}{*}{ Del } & \multicolumn{2}{|c|}{ mean \pm SD } & \\
\hline & $12.48 \pm 13.16$ & $2.24 \pm 3.84$ & $0.0000^{*}$ \\
\hline Del component D1 + D2 + D3 & $5.65 \pm 6.92$ & $1.81 \pm 3.03$ & $0.0009^{\star}$ \\
\hline Others & \multicolumn{2}{|c|}{$n / \%$} & \\
\hline taurodontism & $12 / 20.00$ & $3 / 5.00$ & $0.0135^{*}$ \\
\hline mesiodens & $1 / 1.67$ & $0 / 0.0$ & 0.3254 \\
\hline Dentinoma & $18 / 30.0$ & $9 / 15.0$ & 0.0505 \\
\hline Impacted teeth & $6 / 10.00$ & $2 / 3.33$ & 0.1466 \\
\hline
\end{tabular}

*statistically significant differences; $p \leq 0.05$

ally healthy patients did not present any important premolar root resorption or $\mathrm{V}$-shaped roots. The analysis of Spearman's rho revealed a positive correlation between dental root resorption and age at treatment start, and the use of vincristine, cyclophosphamide, ifosfamide, cisplatin P, and their doses. Early chemotherapy complications had no impact on this congenital defect (Table 3). A similar analysis of severe and extremely severe root resorption revealed a positive correlation also with doxorubicin, etoposide, teniposide, and vomiting (Table 3). The D1 + D2 + D3 component of Del was correlated with vincristine, cyclophosphamide, doxorubicin, ifosfamide, etoposide, and cisplatin use, age at treatment start, sometimes treatment duration, and grade 3 mucositis (Table 3 ).

Tooth agenesis occurred also more often in patients after chemotherapy than in controls (Table 2). Hypodontia ( $<6$ missing teeth) occurred in $15 \mathrm{PCH}$ patients and 5 controls; oligodontia (8 missing teeth) in one. In PCH on average $2.87 \pm 1.6$ teeth were missing, and in CG $1.6 \pm 0.55$ (statistically significant difference; $p=0.0023$ ). Premolars were most often missing in PCH (12/16 patients); second molars (4/16) and mandibular incisors (2/16) were missing less often. For one patient from that group both premolars and second molars were affected, while for another one, premolars, second molars, and incisors were affected. In controls, premolars (3/5) and maxillary lateral incisors $(2 / 5)$ were missing. Maxillary teeth were missing more often than mandibular ones. Five PCH patients had both maxillary and mandibular teeth missing. Spearman's rho established a positive correlation between the absence of 
Table 4. Statistically significant Spearman's rho determining the correlation between tooth congenital disorders and the used antineoplastic treatment, age at treatment start, treatment duration, and early complications

\begin{tabular}{|c|c|c|c|c|c|c|}
\hline & \multicolumn{3}{|c|}{ Root resorption } & \multirow{2}{*}{$\begin{array}{c}\text { Tooth } \\
\text { agenesis }\end{array}$} & \multirow[t]{2}{*}{ Microdontia } & \multirow[t]{2}{*}{ Del } \\
\hline & D1, D2, D3 & D2 and D3 & Del D1 + D2 + D3 & & & \\
\hline Age at start & $0.1844^{*}$ & $0.3600^{*}$ & $0.2823^{*}$ & $0.1981^{*}$ & 0.1050 & $0.3664^{\star}$ \\
\hline Treatment duration & 0.1520 & $0.3089^{*}$ & $0.2459^{*}$ & $0.2415^{\star}$ & $0.3099^{*}$ & $0.4276^{\star}$ \\
\hline Time since treatment completion & $0.2459^{\star}$ & $0.4413^{*}$ & $0.3462^{*}$ & $0.3726^{*}$ & $0.4801^{*}$ & $0.5802^{*}$ \\
\hline VCR & $0.2517^{*}$ & $0.4049^{*}$ & $0.3746^{*}$ & $0.2777^{*}$ & $0.3748^{*}$ & $0.5487^{*}$ \\
\hline Dose & $0.2327^{*}$ & $0.3427^{*}$ & $0.3517^{*}$ & $0.2756^{\star}$ & $0.3322^{*}$ & $0.4962^{*}$ \\
\hline CTX & $0.2866^{\star}$ & $0.4054^{\star}$ & $0.4029^{*}$ & $0.2724^{\star}$ & $0.3702^{*}$ & $0.5047^{\star}$ \\
\hline Dose & $0.2796^{*}$ & $0.4032^{*}$ & $0.3992^{*}$ & $0.2632^{*}$ & $0.3678^{*}$ & $0.4852^{*}$ \\
\hline ADM & 0.1601 & $0.3931^{*}$ & $0.2850^{\star}$ & $0.2148^{\star}$ & $0.3025^{\star}$ & $0.4385^{\star}$ \\
\hline Dose & 0.1504 & $0.3722^{*}$ & $0.2632^{*}$ & $0.1990^{*}$ & $0.2549^{\star}$ & $0.3942^{*}$ \\
\hline DTIC & 0.1673 & $0.1817^{*}$ & 0.1784 & 0.1389 & 0.1036 & $0.2228^{*}$ \\
\hline Dose & 0.1758 & $0.1843^{*}$ & $0.1807^{\star}$ & 0.1544 & 0.1296 & $0.2290^{*}$ \\
\hline IF & $0.2257^{*}$ & $0.4115^{*}$ & $0.2989^{*}$ & $0.2111^{*}$ & $0.2394^{*}$ & $0.3491^{*}$ \\
\hline Dose & $0.2135^{*}$ & $0.4046^{*}$ & $0.2902^{*}$ & $0.2024^{\star}$ & $0.2062^{*}$ & $0.3339^{*}$ \\
\hline MTX & 0.1111 & 0.1530 & 0.1717 & 0.1491 & 0.0741 & $0.2111^{*}$ \\
\hline Dose & 0.1091 & 0.1505 & 0.1737 & 0.1401 & 0.0709 & $0.2068^{\star}$ \\
\hline VP-16 & 0.1791 & $0.3625^{\star}$ & $0.2999^{*}$ & $0.1763^{*}$ & $0.1911^{*}$ & $0.3597^{*}$ \\
\hline Dose & $0.1977^{*}$ & $0.3631^{*}$ & $0.3062^{*}$ & $0.1917^{*}$ & $0.1919^{*}$ & $0.3636^{\star}$ \\
\hline CDDP & $0.1847^{*}$ & $0.2641^{*}$ & $0.2053^{*}$ & 0.1009 & $0.3078^{*}$ & $0.3193^{*}$ \\
\hline Dose & $0.1949^{*}$ & $0.2784^{*}$ & $0.2030^{*}$ & 0.1346 & $0.3497^{\star}$ & $0.3370^{*}$ \\
\hline 5-FLU & -0.1601 & -0.0863 & -0.1544 & -0.0716 & $0.3025^{*}$ & 0.0942 \\
\hline Dose & -0.1302 & -0.0701 & -0.1255 & -0.0582 & $0.3906^{*}$ & $0.1843^{*}$ \\
\hline VM-26 & 0.1778 & $0.2916^{\star}$ & 0.1714 & 0.1749 & 0.1541 & $0.2176^{\star}$ \\
\hline Dose & $0.1795^{*}$ & -0.0701 & 0.1733 & 0.1748 & 0.1481 & $0.2166^{\star}$ \\
\hline Mucositis & 0.0934 & 0.1649 & 0.1050 & 0.0626 & $0.2489^{*}$ & 0.1303 \\
\hline Grade 2 & 0.0556 & 0.0865 & 0.0149 & 0.0745 & $0.2593^{*}$ & 0.0877 \\
\hline Grade 2,3 & 0.1601 & 0.1694 & $0.2328^{*}$ & 0.0716 & 0.1245 & $0.2252^{*}$ \\
\hline Vomiting & 0.1618 & $0.2010^{*}$ & 0.1767 & 0.0362 & $0.2967^{*}$ & $0.2379^{*}$ \\
\hline
\end{tabular}

tooth buds and the age at treatment start, and sometimes also its duration, and the use of vincristine, cyclophosphamide, doxorubicin, ifosfamide etoposide, and their doses (Table 4). Furthermore, the analysis revealed that for each of these drugs the number of missing teeth increased when the used dose (correlation coefficient for vincristine: 0.2911, cyclophosphamide: 0.2795, doxorubicin: 0.2043 , ifosfamide: 0.2058, etoposide: 0.2041) and treatment duration were increased (correlation coefficient: 0.2526).

Microdontia occurred only in PCH (Table 2). The number of teeth with smaller dimensions ranged between 1 and 8 (mean $4.0 \pm 2.26$ ). In three patients microdontia occurred only in maxillary teeth, and in one only in mandibular teeth. Microdontia of premolars and second molars was most common (in 9/12 and 7/12 respectively, including in 4 patients in both premolars and second molars). One patient presented a reduction in tooth size in maxillary premolars and mandibular incisors. A positive correlation between microdontia and chemotherapy duration, chemotherapeutic use and its doses (VCR, CTX, ADM, IF, VP-16,
CDDP, and 5-FU), vomiting and mucositis (Table 4) was established. The same factors had an impact on the number of microdontic teeth, which increased with chemotherapy duration (correlation coefficient 0.3109) and the dose of the aforementioned drugs (coefficients for vincristine: 0.3309 , cyclophosphamide: 0.3617, doxorubicin: 0.2577 , IF: 0.2010, etoposide: 0.1851, cisplatin: 0.3435, 5-fluorouracil: 0.4099).

A correlation was also established between Del and age at treatment start, treatment duration, the use and dose of vincristine, cyclophosphamide, doxorubicin, ifosfamide, methotrexate, etoposide, cisplatin, and grade 3 mucositis and vomiting (Table 4).

Other congenital disorders most often included taurodontism, which occurred statistically significantly more often $(p=0.0135)$ in PCH than in CG $(20.0 \%$ vs. $5.0 \%)$. Hypertaurodontism was diagnosed in one $\mathrm{PCH}$ patient, and mesotaurodontism in three of them. Hypotaurodontism occurred in other patients after chemotherapy and in controls. A positive correlation between taurodontic teeth and 
child age at treatment start (correlation coefficient 0.3000; $p=0.0009$ ), and vincristine treatment (coefficient 0.2156), and its doses (coefficient 0.2096), was established.

Upon analysis of respective factors related to antineoplastic therapies, it turned out that vincristine treatment and its doses were related to all observed congenital disorders. Treatment with cyclophosphamide, doxorubicin, ifosfamide, and their doses, related to hypodontia, microdontia and root resorption, and enamel defects, also had a strongly negative impact on odontogenesis. Etoposide and cisplatin treatments were related to microdontic teeth, root resorption, and enamel defects; methotrexate use was related only to root resorption and enamel defects; and carboplatin use was related only to dentinoma prevalence and enamel defects. Early complications, such as mucositis and vomiting, promoted root resorption, reduction in tooth size, and enamel defects.

\section{Discussion}

The present study confirmed that chemotherapeutics could perturb odontogenesis, which also reflected the findings of other quoted studies.

Contrary to its results, some researchers did not discover any differences in enamel hypoplasia prevalence in children treated for neoplasms with chemotherapy or chemotherapy combined with radiotherapy and in the general population [13, 27, 50]. According to other researchers, the prevalence of enamel congenital disorders is higher in children who have undergone antineoplastic treatment [38, 51-53].

According to Oğuz et al., some chemotherapeutics may cause congenital enamel defects [36], including vincristine, vinblastine, and cyclophosphamide. In animal research (hamsters 1997), Lyaruu et al. demonstrated that actinomycin D had a negative impact on amelogenesis [26]. In tests on rats receiving intravenous vincristine and vinblastine together with other chemotherapeutics, Greaves noted the presence of growth lines in teeth, correlated with chemotherapeutic treatment duration [54]. However, Marec-Berard et al. did not establish any correlation between drug use and dose and congenital enamel defects [27]. The present study indicates a correlation between hypoplasia and the use of vincristine and methotrexate, and opacities and the use of vincristine, cisplatin, methotrexate, doxorubicin, ifosfamide, and carboplatin. Näsman et al. noted white enamel opacities in $68 \%$ of children under chemotherapy and in $29 \%$ of controls [48]. Similarly, Nunn et al. observed higher prevalence of opacities and hypoplasia in the PCH group than in controls, but those differences were not statistically significant [54]. In the Hutton study (2008), 60.2\% of children in a group of 120 undergoing chemotherapy presented enamel defects. Enamel hypoplasia did not occur as a single defect in any patient [11].

Oğuz et al. established a correlation between child age at treatment start and enamel hypoplasia, which reflects the results of the present study [36]. However, Marec-Berard et al. established, upon observing 27 children treated for different stages of neuroblastoma, and contrary to the results of the present study, that treatment duration had no impact on the prevalence of congenital disorders [27].
Kinirons et al. examined 54 children a long time after they had completed chemotherapy for acute lymphoblastic leukaemia and noted that treatment duration did not have any impact on the number of teeth with congenital enamel defects. They also established that the increase in the number of permanent teeth with enamel opacities was related to remission extension [56].

Doðan et al. assessed the correlation between early complications and enamel hypoplasia (2001). Nine among 85 children treated for acute lymphoblastic leukaemia suffered from mucositis, and five presented enamel hypoplasia [52]. In the present study, complications presented as vomiting and were correlated with opacities, and as grade 2 mucositis correlated with enamel hypoplasia. These complications could lead to malnutrition in children and present secondary amelogenesis disorders.

There are few publications on the impact of chemotherapy itself, without radiation therapy, on tooth bud development and congenital abnormality development. Since chemotherapy protocols include a couple of chemotherapeutics, there is no information on the impact of the respective drugs on odontogenesis. The available research presents all the types and prevalence of dental congenital abnormalities [14, 21-24, 57]. Maciel et al. found congenital abnormalities in $80.4 \%$ of patients treated for lymphoblastic leukaemia [14]. Höltta et al. reported that $100 \%$ of children after chemotherapy presented congenital abnormalities (Del>1) vs. $25 \%$ of controls [21]. Cubucku et al. (2012) compared the Del in children under chemotherapy ( 27 children) and in those under chemo- and radiation therapy (10 children) to Del in controls. According to their study, Del> 1 also occurred in 100\% of patients and in $12.9 \%$ of controls [57]. In the present study, congenital tooth abnormalities, visible on pantomographs, occurred more often in patients after chemotherapy than in controls. However, the percentage of $\mathrm{PCH}$ patients (76.7\%) with congenital tooth abnormalities was lower than the ones assessed by Minicucci et al. (82.9\%) [28] and by Maciel et al. (80.4\%) [14], but higher than the one assessed by Kaste et al. (60.5\%) [38].

Researchers present various Del, which is probably related to different multidrug chemotherapy protocols in different neoplasms. For Höltta et al. [21], the Del was $15.3 \pm 9.3$ in patients under chemotherapy for lymphoblastic leukaemia and $1.8 \pm 3.9$ in controls. These index values were similar to the one in the present study [21]. Mean Del for Hisieh et al. (children treated for lymphoblastic leukaemia) was $24.7 \pm 17.8$ [25], and for Cubucku et al. (children treated for lymphoblastic leukaemia) $10.8 \pm 11.2$ [57].

In the present study, root resorption, occurring in $60 \%$ of patients after chemotherapy, was the most common congenital abnormality observed on pantomographs. In the Cubucku et al. study, congenital root abnormalities occurred more often (86.4\%), but patients under chemotherapy and radiation therapy represented $27 \%$ of the treatment group [57].

Tooth agenesis or microdontia occurred slightly less often than root congenital abnormalities. The prevalence of these defects varied. Höltta assessed microdontia prevalence, in 55 children treated with high chemother- 
apy doses before they turned ten years old, at $44 \%$ and agenesis at $46 \%$. According to Marec-Berrard et al., these percentages were $18 \%$ and $7 \%$ respectively [27]; to Oğuz et al., 44\% and 3\% [36]; to Maciel et al. [14], 50\% and 25\%; and to Cubucku et al., $16.2 \%$ and $13.5 \%$ [57]. In the present study, agenesis occurred in $26.67 \%$ of patients after chemotherapy, and microdontia in $21.67 \%$. These defects most often occurred in premolars and second molars. According to Höltta et al. and Nisihmura et al., that is related to child age at treatment start, and at the same time to the stage of tooth development $[21,24,58]$.

According to Nishimura et al., there existed a strong correlation between age at treatment start and the prevalence of congenital tooth abnormalities. Root resorption occurred most often in treated patients between the age of zero and 11.8 years. In the present study microdontia or tooth agenesis was not reported in patients aged eight years or older. Tooth agenesis/microdontia occurred in $66.7 \%$ of patients under the age of four and treated with standard chemotherapy and in 100\% of those treated with high drug doses. In the $<4<8$ year group, tooth agenesis and microdontia occurred respectively in 18.2 and $25 \%$ of patients [58].

The present study also established that the longer the antineoplastic treatment was, the more frequent and severe were the congenital abnormalities. Every congenital abnormality was strongly correlated to the duration of antineoplastic treatment.

Cubucku et al. [57], and Nishimura et al. [58] did not establish any correlation between conventional chemotherapy duration and odontogenesis disorders. However, Höltta et al. did not analyse the impact of antineoplastic treatment duration on the prevalence of congenital dental disorders [21, 25].

The correlation between microdontia and the number of teeth reduced in size, and early complications of antineoplastic therapies, including vomiting and mucositis, is an interesting one. It has only been assessed by Olczak-Kowalczyk and Dembowska-Bagińska; however, the studies focused on children treated with chemotherapy combined with radiation therapy [59-61].

Congenital tooth abnormalities are said to result from the direct impact of the drug on odontoblasts and from its indirect impact, including early complications of chemotherapy. Höltta assessed, in his PhD thesis, the impact of different drugs on odontoblasts and ameloblasts in hamster teeth [24]. He established that the studied drugs impaired cellular functions only when they were in use; after treatment completion ameloblast and odontoblast functions were restored.

Numerous researchers $[21,25,27,28]$ have also attempted to assess the impact of chemotherapeutics on odontogenesis and tooth formation. Heirh et al. found that most Del values in patients treated with a combination of drugs, including cyclophosphamide, were higher than in those treated without that drug [25]. In their tests on animals, Lyaruu et al. confirmed that actinomycin D had an impact on tooth enamel and dentine formation, causing pre-odontoblast loss [28]. The assessment of the impact of doxorubicin on human dental pulp cells and fibroblasts (varying drug doses) established that this chemotherapeutic caused a considerable reduction of live cells within the dental pulp and fibroblasts [24]. Some researchers [24, 62] suggest that methotrexate does not cause any dental congenital abnormalities. Five-fluorouracil causes mild perturbations in dental structure only during drug administration; once it is no longer administered odontogenesis resumes [24]. There is no information on the impact of ifosfamide and cisplatin on tooth development.

The present study established a positive correlation between VCR, CTX, IF, and CDDP and their doses and root resorption, including its most severe forms. Vincristine, cyclophosphamide, doxorubicin, and isophosphamide presented a correlation with hypodontia, which was confirmed by Höltta's study on hamsters.

Apart from drugs presenting a positive correlation with hypodontia, other chemotherapeutics, such as etoposide, cisplatin, and 5-fluorouracil, had an impact on microdontia. These results were similar to the ones obtained by other researchers [21, 24, 48]. However, etoposide, cisplatin, and ifosfamide were not listed among the drugs whose adverse reactions could cause dental abnormalities, and therefore further studies seemed necessary.

Maciel et al. noted higher prevalence of taurodontic teeth in patients after treatment with solely chemotherapeutics, compared to controls (7.1\% vs. 5.3\%). However, these differences were not statistically significant [14]. In the present study, the prevalence of taurodontism was statistically significantly higher in patients after chemotherapy than in controls ( $20 \%$ vs. $5 \%$ ). A positive correlation between taurodontic teeth and child age at treatment start and vincristine treatment and dose was established. No information is available on the impact of respective chemotherapeutics on the formation of dentinoma and taurodontic teeth. The aforementioned impact of vincristine on pre- and odontoblasts, leading to perturbations in dentin formation, and on ameloblasts explains the results of the present study.

In conclusion, antineoplastic chemotherapy in children and adolescents promotes dentinoma and congenital tooth abnormalities, especially hypodontia, microdontia, root resorption, taurodontism, and congenital enamel defects. Multidrug chemotherapy including cyclophosphamide, doxorubicin, cisplatin, and vincristine has a particularly negative impact on teeth, which increases increases with the increase of the dose, treatment duration, and the severity of early complications, such as mucositis and vomiting.

\section{The authors declare no conflict of interest.}

\section{References}

1. Stiller. Epidemiology and genetics of childhood cancer. Oncogene 2004; 23: 6429-44.

2. SEER Cancer Statistics review 1975-2010. Rieg LAG, et al. (eds.). National Cancer Institute Nethesda MD, 2013. 
3. Kurt BA, Armstrong GT, Cash DK, Krasin MJ, Morris EB, Spunt SL, Robison LL, Hudson MM. Primary care managment of the childhood cancer survivor. J Pediatr 2008; 158: 458-66.

4. Miller JL, McLeod HL. Pharmacogenesis of cancer chemothera py-induced toxity. J Support Oncol 2007; 5: 9-14.

5. Huszno J, Nowara E. Pharmacocinetics and pharmacogenetics in breast cancer patients systemic treatment. Onkol Prakt Klin 2010; 6: 159-70.

6. Pawlicki M, Wiczyńska B. New anticancer drugs - future directions. Nowotwory J Oncol 2001; 51: 507-14 (Polish).

7. Olczak-Kowalczyk D, Perek D, Daszkiewicz M, Adamowicz-Klepalska B, Dembowska-Bagińska B, Daszkiewicz P. Oral pathology in children harboring neoplastic diseases. Own experience. Nowa Stomatol 2003; 4: 175-9 (Polish).

8. Ferlay J, et al. Globocan 2002: Cancer incidence mortality and prevalence wordwide. IARC cancer Nase No 5 Version 2,0. IARC Press, Lyon 2004

9. Teuffel O, Dettling M, Cario G, Stanulla M, Schrappe M, Bühlmann P, Niggli FK, Schäfer BW. Gene expression profiles and risk stratifi cation in childhood acute lymphoblastic leukemia. Haematologica 2004; 89: 801-8.

10. Sonis AL, Waber DP, Sallan S, Trabell NJ. The oral health of longterm survivors of acute lymphoblastic leukemia, a comparision of tree treatment modalies. Eur J Cancer B Oral Oncol 1995; 31B: 250-252.

11. Hutton A. The oral health needs childrens, adolescens and jung adults after cancetr therapy for solid tumor. University of Brimingham 2008. Available at: http://etheses.bham.ac.uk/142/1/Hutton08MPhil.pdf

12. Pajari $U$, Yliniemi R. The risik of dental caries in childhood cancer is not high in the teeth are caries-free at diagnosis. Pediatr Hemato Oncol 2001; 18: 181-5.

13. Macleod RI, Welbury RR, Soames JV. Effects of cytotoxic chemotherapy on dental development. J R Soc Med 1987; 80: 207-9.

14. Maciel JC, de Castro CG Jr, Brunetto AL, Di Leone LP, da Silveira $\mathrm{HE}$. Oral health and dental anomalies in patients treated for leu kemia in childhood and adolescence. Pediatr Blood Cancer 2009, 53: $361-5$

15. Sosnowska-Boroszko A, Gordon A, Siemińska J, et al. Ename abnormalies in permanent dentition of school children. Nowa Stomatol 2002; 3: 116-21 (Polish).

16. Robinson C, Kirkham J, Brookes SJ, Shore R. Chemistry of mature enamel. In: Dental enamel - formation to destruction. Kirkham RC (eds.). J CRC Press 1995; 167-188.

17. Alpaslan G, Alpaslan C, Gögen H, Oğuz A, Cetiner S, Karadeniz C. Disturbances in oral dental structures in patients with pediatric lymphoma after chemotherapy. Oral Surg Oral Med Oral Patol Oral Radiol Endod 1999; 87: 317-321.

18. Olender E, Kamińska A, Urynowska-Tyszkiewicz I, Wanyura H. Histological aspects and the molecular controlling mechanism of the natural dental development. Czas Stomatol 2010; 63: 543-50 (Polish).

19. Pajari U, Lanning M, Larmas M. Prevelence and location of enamel opactities in children after anti-neoplastic therapy. Comm Dent Oral Epidiemiol 1988; 16: 222-6.

20. Höltta P, Alaluusua S, Saarinen-Pihkala UM, Wolf J, Nystrom M, Hovi L. Long-term adverse effects on dentition in children with poor-risk neuroblastoma treated with high-dose chemotherapy and autologous stem cell transplantation with or without tota body irradiation. Bone Marrow Transpl 2002; 29: 121-7.

21. Höltta P, Alaluusua S, Saarinen-Pihkala UM, Wolf J, Nystrom M, Hovi L. Agenesis and microdontia of permanent teeth as late ad verse effects after stem cell transplantation in young children. Cancer 2005; 103: 181-91.

22. Höltta P. Developmental dental defects in children who reside by river polluted by dioxins and furans. Arch Envirom Health 2001; 56: $522-8$

23. Höltta P. Developmental aberrations of permanent teeth after high-dose anticancer therapy in childhood. University of Helsinki 2005. Available at: http://ethesis.helsinki.fi/julkaisut/laa/hamma/ vk/holtta/developm.pdf.
24. Jones TE, Henderson JS, Jahnson RB. Effects of doxorubicin on human dental pulp cells in vitro. Cell Biol Toxicol 2005; 21: 207-14.

25. Hsieh SG, Hibbert DS, Sha P, Ahern V, Arora M. Assotiation of cyclophosphamide use with dental defects and salivary gland dysfunction in recipents of childhood antineoplastic therapy. Cancer 2011; 117: 2219-27.

26. Lyaruu DM, van Duin MA, Bervoets TJ, Woltgens JH, Bronckers AL. Effects of actinomycin D developing hamster molar tooth germs in vitro. Eur J Oral Sci 1997; 105: 52-8.

27. Marec-Berard P, Chaux-Bodard AG, Langrange $H$, Gourmet $R$, Bergeron C. Long-term effects of chemotherapy on dental status in children treated for nephroblastoma. Peditric Hematol Oncol 2005; 22: 581-8.

28. Minicicci EM, Lopez LF, Crocci AJ. Dental abnormalities in children after chemptherapy treatment for acute leukemia. Leuemia Research 2003; 25: 45-50.

29. Jaffe N, Toth BB, Hoar RE, Ried HL, Sullivan MP, McNeese MD. Den tal and maxillofacial abnormalities in long-term survivors of childhood cancer: effects of treatment with chemotherapy and radiation to the head and neck. Pediatr 1984; 73: 816-23.

30. Remmers D, Bökkerink JP, Katsaros C. Microdontia after chemotherapy in a child treated for neuroblastoma. Orthod Craniofac Res 2006; 9: 206-10.

31. Rosenberg S, Kolodney J, Wong GY, Murphy L. Altered dental root development in long-term survivors of pediatric acute lymphoblastic leukemia. Cancer 1987; 59: 1640-8.

32. Najafi SH, Tohidastakrad Z, Momenbeitollahi J. The long-term effects of chemo radiotherapy on oral health and dental development in childhood cancer. J Dent (Teheran) 2011; 8: 39-43.

33. Hwang SY, Yoon RK. Develppmental dental defects linked with chemotherapy: a case report. J Clin Pediatr Dent 2011; 35: 309-13.

34. Maguire A, Welbury RR. Long-term effects of antineoplasic chemotherapy and radiotherapy on dental development. Dent Update 1996; 23: 188-94.

35. Ilgenili T, Oren H, Uysal K. The acute effects of chemotherapy upon the oral cavity: Prevention and management. Turk J Cancer 2001; 31: 93-105.

36. Oğuz A, Cetiner S, Karadeniz C, Alpaslan G, Alpaslan C, Pinarli G. Long-term effects of chemotherapy on orodental structures in children with non-Hodkin's Lymphoma. Eur J Oral Sci 2004; 112: 8-11.

37. Sonis AL, Tarbell N, Valachovic RW, Gelber R, Schewnn M, Sallam S. Dentofacial development in long term survivors of acute lymphoblastic leukemia. Cancer 1990; 60: 2645-52.

38. Kastle SC, Hopkins KP, Jones D, Crom D, Greenwald CA, Santana VM. Dental abnormalities im children treated for acute lymphoblastic leukemia. Leuk 1997; 11: 792-6.

39. Lukinmaa PL, Sahlberg C, Leppäniemi A, Partanen AM, Kovero O, Pohjanvirta R, Tuomisto J, Alaluusua S. Arrest of rat molar tooth development by lactational exposure to 2,3,7,8-tetrachlorodibenzo-p-dioxin. Toxicol App Pharmacol 2001; 173: 38-47.

40. Nieminen P, Arte S, Tanner D, Paulin L, Alaluusua S, Thesleff I, Pirinen S. Identification of a nonsense mutation in the PAX9 gene in molar ologodontia. Eur J Hum Genetic 2001; 9: 743-6.

41. Partanen AM, Kiukkonen A, Sahlberg C, Alaluusua S, Thesleff I, Pohjanvirta R, Lukinmaa PL. Developmental toxicity of dioxin to mouse embryonic teeth in vitro: arrest of tooth morphogenesis involves stimulation of apoptotic program in the dental epithelium. Toxicol App Pharmacol 2004; 194: 24-33.

42. Lammi L, Arte S, Somer M, Jarvinen H, Lahermo P, Thesleff I, Pirinen S, Nieminen P. Mutation in AXIN2 couse familial tooth agenesis and predispose to colorectal cancer. Am J Hum Genet 2004; 74: 1043-50.

43. Boyle P, Ferlay A. Cancer incidence and mortality in Europe. Ann Oncol 2004; 16: 481-8.

44. Stachowicz-Stencel T, Stefanowicz J, Bień E, Balcerska A. Long-term effects of the treatment malignant neoplasm in children. Forum Med Rodz 2009; 3: 485-93 (Polish).

45. Jemal A, Siegeil R, Ward E, Muray T, Xu J, Thun MJ. Cancer statistics. Cancer J Clin 2007; 57: 43-66.

46. Liu YJ, Zhu GP, Guan XY. Comparision of the NCI-CTCAE version 4.0 and version 3.0 in assessing chemioradiation-induced oral mucosi- 
tis for localy advanced nosopharyngeal carcinoma. Oral Oncol 2012; 48: 554-9.

47. A review of the developmental defects of enamel index (DDE Index). Commission on Oral Health, Research \& Epidemiology. Report of an FDI Working Group. Int Dent J 1992; 42: 411-26.

48. Näsman M, Forsberg CM, Dahllöf G. Long-term dental development in children after treatment for malignant disease. Eur J Orthod Sci 1997; 19: 151-9.

49. Dahllof G, Nasman M. Effect of chemotherapy of dental maturiny in children with hematological malignancies. Pediatr Dent 1989; 11: 303-6.

50. Lauritano D, Petruzzi M. Decayed, missing and filled teeth index and dental abnormalies in long-term survivors leukemic children: a prospective controlled study. Med Oral Patol Cir Bucal 2012; 17: e977-80.

51. Al-Ghani BA, Hasan NM, Hassan JM. Enamel hypoplasia in patients with acute lymphoblastic leukemia. J Bagh Colleg Dent 2005; 17: 53-6.

52. Doðan C, Haytac C, Antem B, Babmaz Y, Tanyely A. Oral health in children with acute lymphoblastic leukemia and lymphoma. Turk J Hematol 2001; 18: 179-83.

53. Avşar A, Elli M, Darka O, Pinarli G. Long-term effects of chemotherapy on caries formation, dental development, and salivaryfactors in childhood cancer survivors. Oral Surg Oral Med Oral Pathol Oral Radiol Endod 2007; 104: 781-9.

54. Greaves P. Mouth and oropharynx. Greaves P (ed.). Histopatology of precinial toxity studies. AP: 2012; 325-332.

55. Nunn JH, Welbury RR, Gordon PH, Kernahan J, Craft AW. Dental caries and dental anomalies in children treated by chemotherapy fo malignant disease: a study in the north of England. Int J Paediatr Dent 1991; 1: 131-5.

56. Kinirons MJ, Fleming P, Boyd D. Dental caries experience of children in remission from acute lymphoblastic leukaemia in relation to the duration of treatment and the period of time in remission. Int J Paediatr Dent 1995; 5: 169-72.

57. Cubucku CE, Sevinir B, Ercan I. Didtarbend dental development of permanent teeth in children with solid tumors and lymphas. Pediatr Blood Cancer 2012; 58: 80-4.

58. Nishimura S, Inada H, Sawa Y, Ishikawa H. Risk faktors to cause of tooth anomalies in chemotherapy of paediatric cancers. Eur J Cancer Care 2013; 22: 353-60.

59. Dembowska-Bagińska B. Health status and psychosocial problems of children and adolescents after treatment of malignant childhood central nervous system tumors. The Children's Memorial Health Institute Warsaw, 2008 (Polish).

60. Dembowska-Bagińska B. Long-term affect of multimodal treatment of childhood malignancies. Stand Med 2001; 3: 45-51 (Polish).

61. Olczak-Kowalczyk D, Daszkiewicz M, Adamowicz-Klepalska B, Mielnik-Błaszczyk M, Dembowska-Bagińska B, Perek D. The status of dentition and oral hygiene in children after anticancer treatment. Ann Acad Med 2004; 34: 237-55 (Polish).

62. Woltgens JH, Lyaruu DM, Bronckers AL, Duin MA. Effects of methotrexate on cell proliferation in developing hamster tooth germs in vitro. Eur J Oral Sci 1998; 106: 156-9.

\section{Address for correspondence}

\section{Ewa Krasuska-Stawińska}

The Childrens' Memorial Heath Institute

Al. Dzieci Polskich 20

04-730 Warsaw, Poland

e-mail: e.krasuska@czd.pl

Submitted: 23.03 .2015

Accepted: $\quad 30.11 .2015$ 